\title{
Eye movements and vestibulo-ocular reflex in the blind
}

\author{
D.Kömpf ${ }^{1}$ and H.-F. Piper ${ }^{2}$ \\ ${ }^{1}$ Neurologische Universitätsklinik Erlangen, Schwabachanlage 6, D-8520 Erlangen, Federal Republic of Germany \\ ${ }^{2}$ Universitäts-Augenklinik Lübeck, Ratzeburger Allee 160, D-2400 Lübeck, Federal Republic of Germany
}

Summary. To assess the effect of chronic deprivation of visual feedback, 21 blind patients underwent clinical and electronystagmographical examination. Patients with congenital blindness were characterized by spontaneous eye movements, inability to consciously move the eyes and absence of the vestibulo-ocular reflex (VOR), whereas eye movement abnormalities were practically absent in those with blindness acquired late in life. Active visual experience, at least in early life, seems to be crucial for the development of eye movements and VOR adjustment.

Key words: Development of eye movements - Blindness Vestibulo-ocular reflex

It is now well established that active visual experience is necessary for normal development of the mammalian visual system [20]. It is thus surprising that there have been few observations concerning the development of the oculomotor system in the absence of vision.

Bartels [1,2] and Ohm [15] were the first to study eye movements systematically in blind subjects. They noted that particularly those who were congenitally blind or had lost their vision at an early age showed a variety of oculomotor abnormalities: nystagmus, eye deviations and so-called gross fluttering or wandering eye movements. Forssman [7] and Toglia [19] observed weak or absent vestibulo-ocular reflexes (VOR). Corresponding spontaneous nystagmus phenomena in the dark were described in dark-reared cats before these had had any visual experience $[11,12]$, whereas the VOR was present immediately at the end of the light-deprived period (2-15 months) in kittens, cats and rabbits $[4,5,11,12]$.

To assess the effect of chronic deprivation of visual feedback in humans we studied certain aspects of oculomotor control in blind subjects clinically and by electronystagmography. We also considered whether the experimental data recorded in dark-reared animals could serve as a model for oculomotor abnormalities in the blind.

\section{Materials and methods}

In this study 21 patients (a 7-year-old boy and 20 adults $34-82$ years of age) who had been blind from birth $(n=4)$ or had lost their vision in later life $(n=17)$ following diseases affecting the anterior visual pathways were investigated; 14 of the latter group still had partial vision in at least one eye (visual acuity $<1 / 35)$ or light perception only $(n=7)$.

Electro-oculography (EOG) was possible in 14 subjects. Eye movements were recorded by AC/DC EOG (AC: time

Offprint requests to: D. Kömpf constant: $3 \mathrm{~s}$, DC: bandwidth $-30 \mathrm{kHz}$ ) with surface silversilver electodes placed in the inner and outer canthi of each eye (monocular recording). An approximate calibration was obtained with $40^{\circ}$ right/left used for lateral gaze. Optokinetic nystagmus was elicited by means of a light band projector and panoramic screen at different surround velocities $\left(30^{\circ}-120^{\circ}\right)$. In 7 subjects the corneo-retinal potential was attenuated because of the ocular diseases; the vestibulo-ocular responses to rotational tests and sinusoidal horizontal angular rotations (using Tönnies rotating chair) were here observed under Frenzel glasses.

Clinical observations and examinations (neurological, ophthalmological) were supplemented by photography and in part by motion pictures. Orbital CT was performed in the congenitally blind subjects to study the condition of the extraocular muscles. In addition an EEG was performed in every case.

\section{Results}

The blind subjects could be divided into three major groups (Table 1): A, total blindness since birth (cases $1-4, n=4$ );
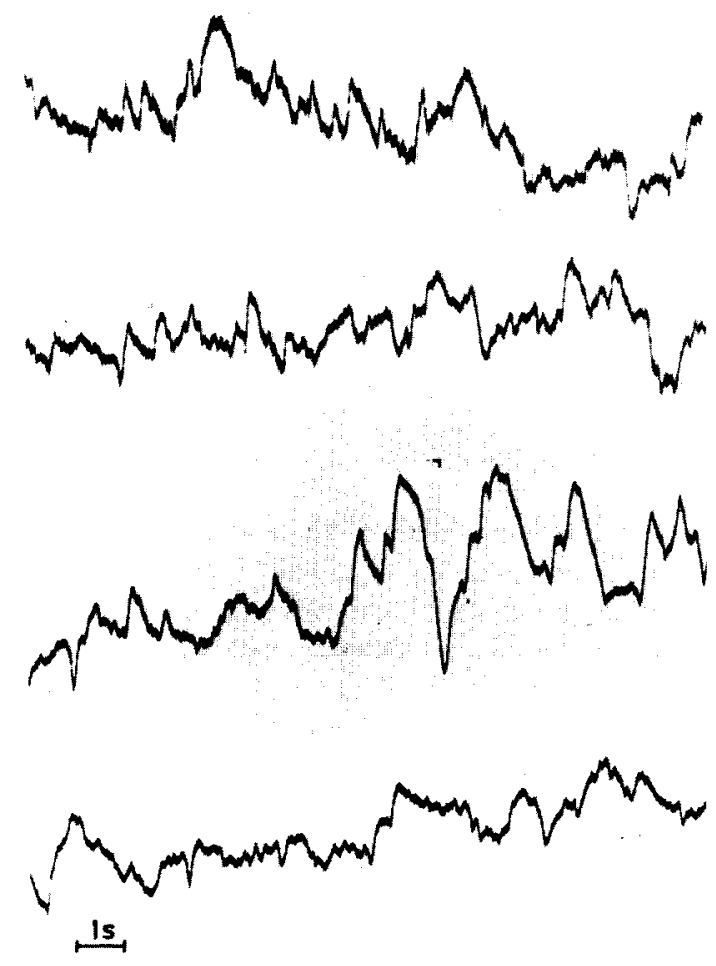

Fig. 1. Constantly moving eyes affected by congenital blindness: nystagmus and slow searching eye movements. (Patient 1, aged 7 years; EOG, monocular AC recording, left eye horizontal) 
Table 1. History of visual loss and ophthalmological diagnosis for each patient

\begin{tabular}{|c|c|c|c|c|c|c|c|c|}
\hline Patient & Age & $\begin{array}{l}\text { Period of } \\
\text { blindness } \\
\text { (years) }\end{array}$ & $\begin{array}{l}\text { Light } \\
\text { perception }\end{array}$ & $\begin{array}{l}\text { Visus } \\
<1 / 35\end{array}$ & $\begin{array}{l}\text { Spontaneous } \\
\text { eye } \\
\text { movements }\end{array}$ & $\mathrm{OKN}$ & VOR & Diagnosis \\
\hline 1 & 7 & Congenital & o & o & + & o & o & Retrolental fibroplasia \\
\hline 2 & 53 & Congenital & o & o & + & 0 & o & $\begin{array}{l}\text { Gonoblenorrhoea; staphyloma, left; } \\
\text { phthisis bulbi, right }\end{array}$ \\
\hline 3 & 64 & Congenital & o & o & + & o & o & Buphthalmos \\
\hline 4 & 65 & Congenital & o & o & + & 0 & o & Total leukoma \\
\hline 5 & 47 & 38 & o & o & + & o & o & Phthisis bulbi \\
\hline 6 & 65 & 10 & o & o & + & o & o & Atrophy of retina and choroid \\
\hline 7 & 78 & 73 & + & 0 & + & 0 & $(+)$ & Total leukoma; atrophy of optic nerve \\
\hline 8 & 70 & 65 & + & + & + & $?$ & $(+)$ & Pernicious myopia \\
\hline 9 & 65 & 64 & Left + & Right + & + & Inversion & $(+)$ & Aphakia; congenital cataract \\
\hline 10 & 64 & 24 & $(+)$ & o & + & o & + & Retinitis pigmentosa \\
\hline 11 & 63 & 33 & o & o & + & 0 & $(+)$ & Phthisis bulbi; congenital syphilis \\
\hline 12 & 47 & 10 & $\begin{array}{l}\text { Right }+ \\
\text { Left } o\end{array}$ & o & + & $?$ & + & $\begin{array}{l}\text { Dysgenesis of mesoderm of iris and cornea } \\
\text { (Rieger) }\end{array}$ \\
\hline 13 & 47 & $\begin{array}{l}\text { Left congenital, } \\
\text { right } 10\end{array}$ & $\begin{array}{l}\text { Left }+ \\
\text { Right o }\end{array}$ & $\mathbf{o}$ & + & + & $(+)$ & Detachment of the retina; cataract \\
\hline 14 & 82 & 22 & + & $\mathbf{o}$ & o & + & + & Retinitis pigmentosa \\
\hline 15 & 34 & 19 & + & $?$ & o & + & + & Encephalitis \\
\hline 16 & 73 & 5 & Left + & Right + & o & + & + & Retinitis pigmentosa \\
\hline 17 & 49 & $?$ & + & + & o & + & + & Atrophy of the optic nerve \\
\hline 18 & 81 & 4 & + & o & o & + & $(+)$ & Detachment of the retina; glaucoma \\
\hline 19 & 45 & 4 & + & o & o & + & + & Atrophy of the optic nerve \\
\hline 20 & 82 & 3 & + & + & o & + & + & Senile macular degeneration; cataract \\
\hline 21 & 63 & 1 & + & o & o & + & + & Detachment of the retina; glaucoma \\
\hline
\end{tabular}

OKN, optokinetic nystagmus; VOR, vestibulo-ocular reflex; o, no response; (+), weak response (postrotatory nystagmus < $15 \mathrm{~s}$ ); + , normal response

Table 2. Oculomotor signs in patients with blindness acquired at an early age

\begin{tabular}{|c|c|c|c|c|c|c|c|}
\hline \multirow{2}{*}{$\begin{array}{l}\text { Patient } \\
5\end{array}$} & \multicolumn{2}{|c|}{ Nystagmus } & \multirow{2}{*}{$\begin{array}{l}\begin{array}{l}\text { Gross fluttering } \\
\text { movements }\end{array} \\
\text { Slow vertical oscillations }\end{array}$} & \multirow{2}{*}{$\begin{array}{l}\text { Constant deviation } \\
\mathrm{o}\end{array}$} & \multirow{2}{*}{$\begin{array}{l}\text { Sensing } \\
\text { position }\end{array}$} & \multirow{2}{*}{$\begin{array}{l}\begin{array}{l}\text { Voluntary } \\
\text { saccades }\end{array} \\
+\end{array}$} & \multirow{2}{*}{$\begin{array}{l}\text { Self induced } \\
\text { pursuit }\end{array}$} \\
\hline & $j / p$ & (vert./mon.) & & & & & \\
\hline 6 & $\mathrm{j}$ & (horiz./mon.) & o & Add., left eye & + & + & + \\
\hline 7 & j & & 0 & Abd., right eye & o & 0 & o \\
\hline 8 & $\mathrm{j}$ & (rev. dir.) & 0 & Add., right eye & + & + & $(+)$ \\
\hline 9 & $\mathrm{p}$ & (horiz./mon.) & o & Esodeviation left $<$ right & + & + & + \\
\hline 10 & $\mathrm{j}$ & (oblique, rev.dir.) & o & Upwards to right & $(+?)$ & + & $(+)$ \\
\hline 11 & $\mathrm{j}$ & & 0 & Divergence & + & + & + \\
\hline 12 & $\mathrm{j} / \mathrm{p}$ & (rev. dir.) & o & o & + & + & + \\
\hline 13 & & & 0 & 0 & + & + & + \\
\hline
\end{tabular}

j, jerk; p, pendular; vert., vertical; horiz., horizontal; mon., monocular; rev. dir., direction reversing; Add., adduction; Abd., abduction

$\mathrm{B}$, early acquired blindness (cases $5-13, n=9$ ); C, late acquired blindness (cases 14-21, $n=8$ ) with better preserved light perception or partial visual loss only (visual acuity $<1 /$ 35 ). The subjects in group $\mathrm{C}$, in particular, were not completely blind (Lichtblindheit; Ohm [15]), but were functionally blind for social, practical purposes (Sehblindheit; Ohm [15]).

\section{Total blindness since birth}

All subjects exhibited constant eye deviations, even though it was difficult to judge the exact position of the malformed globes in cases 2-4. All subjects further exhibited slow oscillations of the eyes (Table 1). Particularly in cases 1 and 2, these eye movements were completely irregular, arrhythmic, un- coordinated and not continuous. The eyes moved in all directions at different speeds, stopped at any point and started again without any recognizable reason (Fig. 1). Particularly in lateral gaze, a predominantly horizontal jerk nystagmus was superimposed in the direction of gaze. The amplitude of the eye movements varied between the two eyes in some cases. One subject (patient 2) also showed circular or elliptical movements. None exhibited pendular nystagmus. They tended to maintain partial eyelid closure at all times.

None of these subjects had any perception of the spontaneous eye movements or knew the actual eye position at any time. They were not able to voluntarily initiate saccades or to track their outstretched thumb in a self-induced movement. There was no VOR in any of these cases even though the sensation of self-rotation was preserved. 

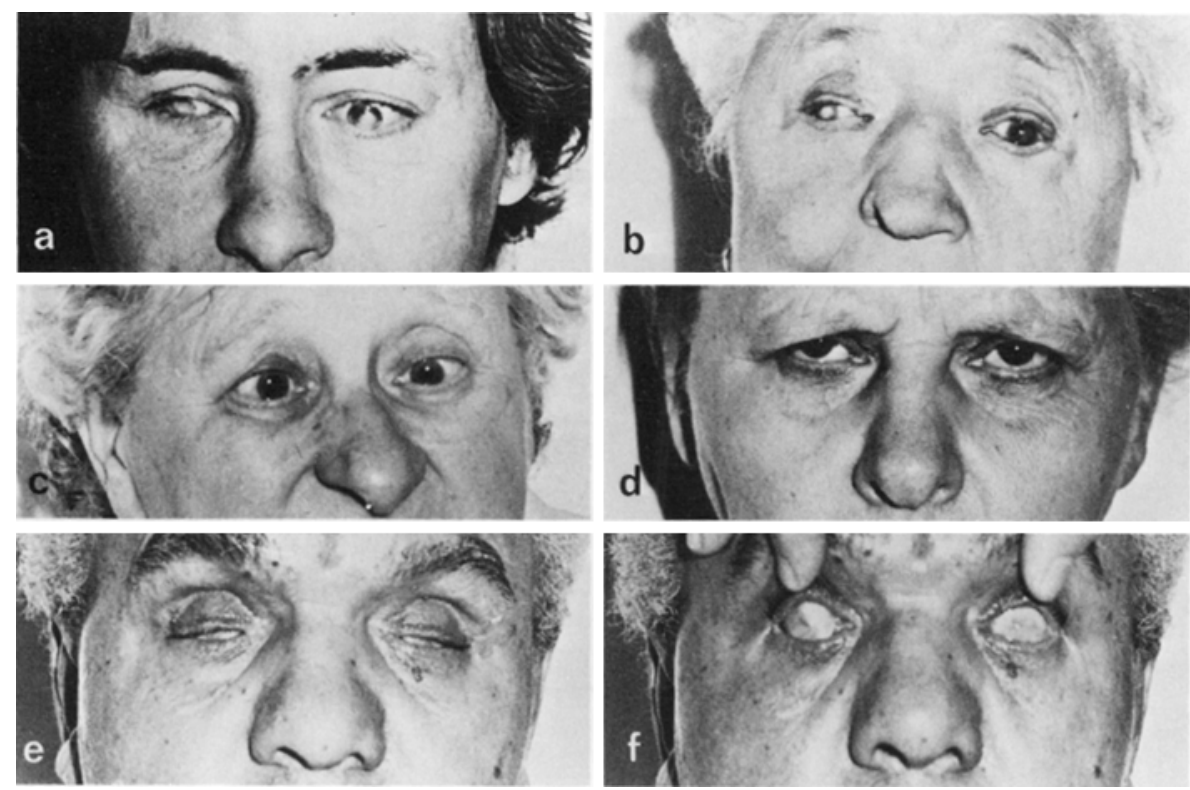

Fig. 2a-e. Constant eye deviations in blindness acquired early in life.

a Patient 5 ; b patient 7 ; c patient 8 ; d patient $10 ; \mathbf{e , ~} \mathbf{f}$ patient 11

\section{Early acquired blindess}

In this inhomogeneous group (Tables 1,2) blindness had been present for up to 73 years (mean 36.3 years): Four patients had become blind during their teens; in the remaining five patients, however, blindness dated from around the 30th up to the 55th year of life. Three patients had become completely blind, four had lost all but light perception, and three had some residual vision in at least one eye. An optokinetic response could not be elicited in any case. There was a constant deviation of the eyes in most subjects (Fig. 2). Six patients showed a slight spontaneous downward gaze preference (cases $5,7,8,9)$ combined with weak upward movements. All patients but one (case 7) were able to sense the eye position, to consciously direct the eyes within the orbit (Fig.3) and to track their outstretched thumb. Patient 7 had lost her sight 73 years before in her 5th year of life, and did not have any memory of vision. None of the patients in this group exhibited the gross fluttering eye movements seen in group A. In one patient irregular vertical oscillations occurred with faster downward speed. All subjects showed spontaneous nystagmus (Table 2): jerk nystagmus was observed in eight and pendular nystagmus in three patients, while two exhibited mixed pendular and jerk nystagmus. Shimmering [3] frequent $(8-9 \mathrm{~Hz})$ low amplitude $\left(2-4^{\circ}\right)$ nystagmus was found in one case (patient 12 ) superimposed on horizontal spontaneous jerk nystagmus. In another case (patient 9) the pendular nystagmus showed typical features of congenital nystagmus (Fig. 4). The chiefly horizontal jerk nystagmus reversed direction irregularly in three cases. Monocular nystagmus was exclusively vertical in one case (Fig. 5), and in another case predominantly in an oblique direction (Fig. 3).

In general the VOR was markedly reduced (postrotatory nystagmus $<15 \mathrm{~s}, n=5)$ or absent $(n=2)$. In two patients, however, the response lasted more than $30 \mathrm{~s}$ in both directions.

\section{Late acquired blindness}

This group exhibited a remarkably inconspicuous oculomotor behaviour in spite of the marked visual restriction. They were able to maintain a steady eye position (Fig.6) without any spontaneous eye movement phenomena, to sense the eye position, and to start and execute saccades and self-induced slow eye movements voluntarily. The VOR was normal and the optokinetic response present in every case.

\section{Electroencephalography}

In group $A$ and $B$ the EEG generally showed a low-amplitude dominant occipital alpha rhythm of 20-30uV. Patient 9 was the only one with amplitudes up to $80-120 \mathrm{uV}$; eye opening by this patient induced clear alpha blockage, whereas there was no reliable blockage reaction in the other cases. In group $\mathrm{C}$ the patients showed a slightly higher occipital alpha amplitude of $40-80 \mathrm{uV}$.

\section{Conclusions}

To ensure stable fixation of gaze in a freely moving and seeing subject, eye movements are continually elicited utilizing retinal and vestibular contributions, namely the VOR, stimulated by head motion to elicit compensatory eye movements, and visual pursuit, stimulated by movement of the visual surroundings to evoke tracking eye motion. The development of smooth pursuit lags behind the development of the vestibular system.

Although control of eye position is abolished in blind subjects, those with late acquired visual loss can maintain a stable eye position. They sense the actual eye position in the orbit and are able to voluntarily start and execute saccades. They can also pursue their own outstretched thumb, probably both using knowledge of the motor command to the limb and proprioceptive input $[8,18]$. The oculomotor behaviour is comparable to that of healthy individuals moving their eyes in total darkness.

Without prior vision, however, the sense of eye position or change in direction of gaze does not develop and therefore voluntary saccades cannot be made, although the mechanism of nystagmus quick phase is preserved. Furthermore, all congenitally blind subjects develop both anarchic slow searching 


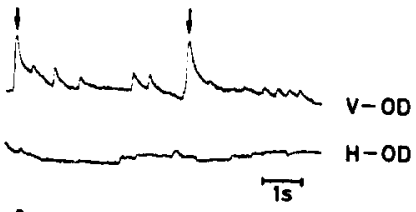

A

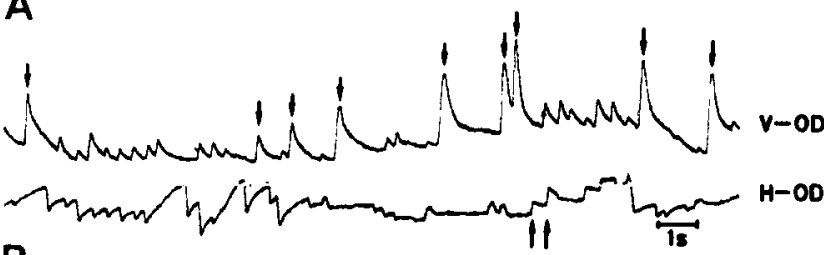

B

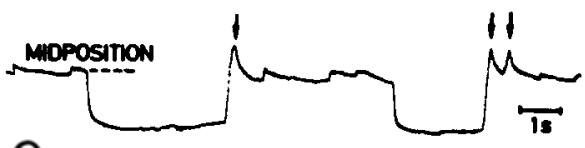

$\mathrm{C}$
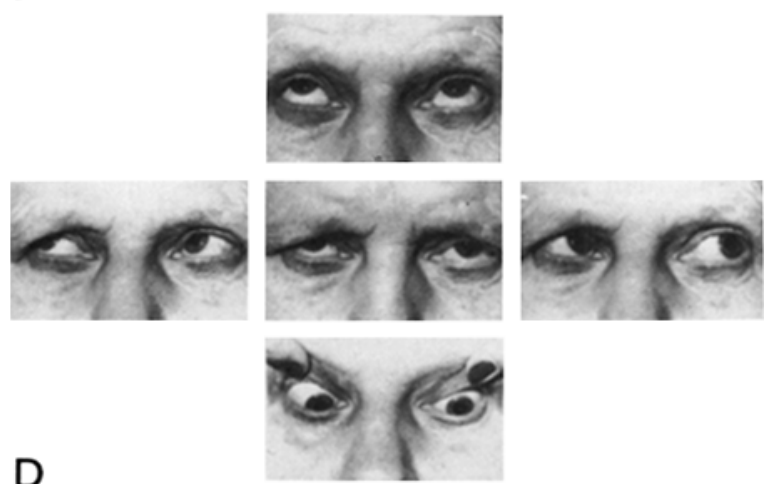

D

Fig.3A-D. Early acquired blindness (patient 10).A Spontaneous vertical nystagmus; $\mathbf{B}$ irregular oblique nystagmus (vertical: up; horizontal: irregularly reversing direction (arrows); $\mathbf{C}$ voluntarily initiated saccades to the left; $\mathbf{D}$ voluntary saccades $($ arrows $=$ blinks, $V$, vertical; $H$, horizontal; $O D / S$, oculus dexter/sinister)

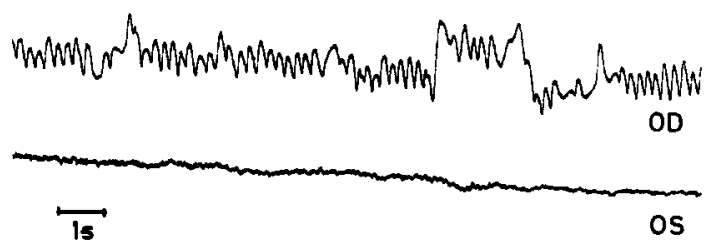

A
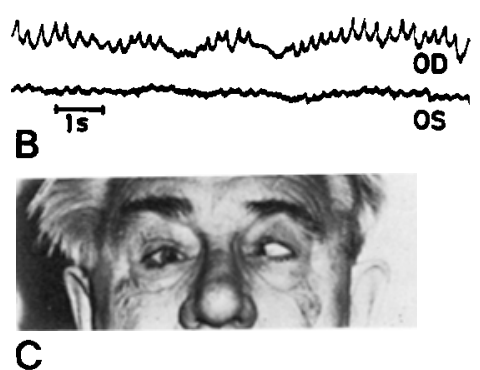

Fig.4A-C. Pendular nystagmus in blindness (patient 9). A Monocular pendular nystagmus of right eye; left eye resting in constant extreme esodeviation (both eyes open); B pseudocycloid nystagmus of right eye (closed) and pendular nystagmus of left eye (open); $\mathbf{C}$ left eye in constant extreme esodeviation (for abbreviations see Fig. 3)

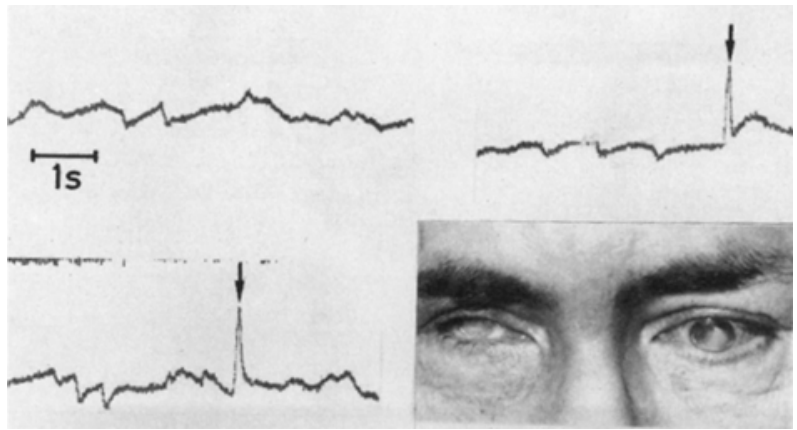

Fig.5. Monocular vertical spontaneous mixed pendular and jerk nystagmus in early acquired blindness. (Patient 5 , monocular vertical EOG recording from left eye; arrow indicates a blink)

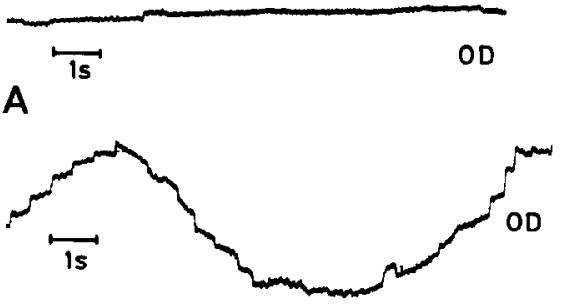

B
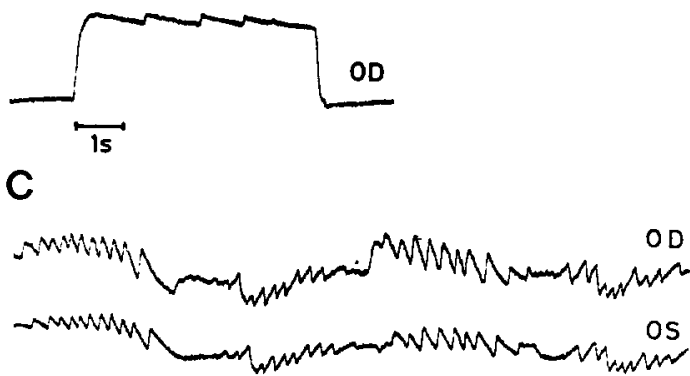

D

Fig.6A-D. Eye movements in a late-acquired blindness (patient 16). A stable primary eye position; B self-induced pursuit; $\mathbf{C}$ saccade to the right and back to primary position; $\mathbf{D}$ vestibular response to sinusoidal chair oscillation (for abbreviations see Fig. 3)

eye movements and nystagmus phenomena. In our cases and those of other workers $[9,17]$ only jerk nystagmus was observed. Ohm [15] is so far the only one to have described congenital visual loss and pendular nystagmus (in three patients). This type of nystagmus seems more likely to develop if at least some light perception is preserved. In dark-reared cats superimposed pendular nystagmus was only observed after light exposure [11].

The pathogenesis of both types of eye movements is still unclear. The similarities between the eye movements of blind subjects and patients with cerebellar lesions led Leigh and Zee [14] to suggest that the deprivation of visual inputs to the cerebellum could produce similar oculomotor disturbances to cerebellar lesions. Indeed, the eye movement recordings of a patient with opsoclonus can be indistinguishable from those of congenitally blind persons [13]. 

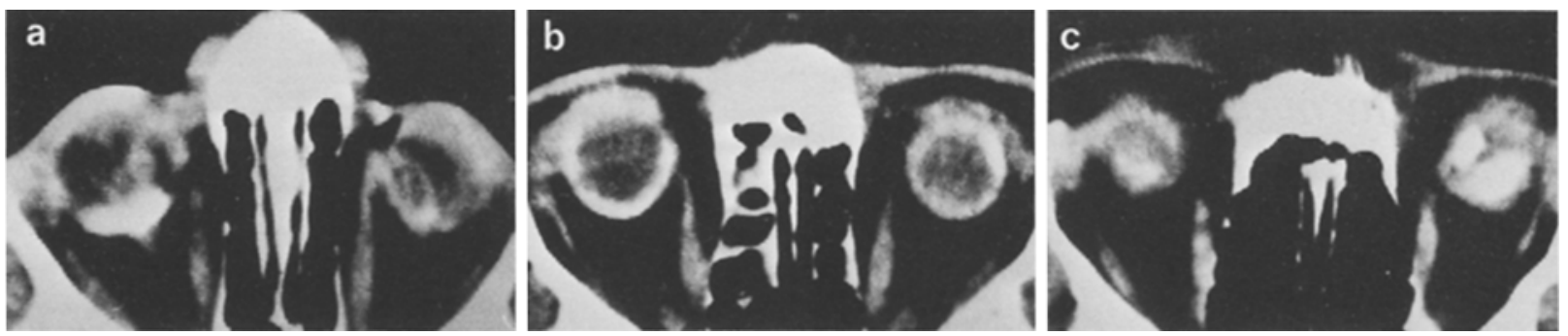

Fig. 7a-c. Orbital CT in three cases of congenital blindness: marked atrophy of optomotor muscles. a Patient 1; b patient 2; $\mathbf{c}$ patient 3

Individuals who become blind early in life almost invariably develop spontaneous nystagmus over the course of many years, but anarchic slow oscillations do not occur and both perception of eye position and the ability to direct the eyes in the orbit voluntarily are preserved. The ratio of jerk to pendular nystagmus is about 4-5:1 or even higher; thus pendular nystagmus is rather rare. Both types of nystagmus can alternate in the same individual or frequent pendular oscillations can also be found superimposed on jerk nystagmus beats, as in patient 12 (published earlier in detail [16]). Quite often the horizontal jerk nystagmus reverses direction irregularly.

Since the underlying ocular disease often progresses slowly and the final occurrence of blindness cannot be determined exactly, the point at which nystagmus develops can generally only be estimated. In blind people, the VOR becomes functionally meaningless, since they do not need stabilization of the visual world while they are moving. In spite of this, dark-reared animals have a qualitatively normal VOR. Quantitatively, however, the VOR gain is reduced to one-third and the rate of decline of postrotatory nystagmus induced by a velocity step is much faster than in normally raised animals $[4-6,11,12]$. Obviously, an essential part of the vestibular control of eye movements can develop primarily, independently of visual experience, but the experimental results also indicate that visual experience and visuo-vestibular interaction is necessary for VOR development and VOR adjustment: first, the deprivation has to have occurred with no prior vision and, second, the duration of dark-rearing seems to be crucial in determining the amount of functional deficit.

Confirming earlier clinical observations $[7,14,19]$ but in contrast to the experimental data, we found total abolition of the VOR in the congenitally blind. Since the VOR is an operating open-loop system, thus generally requiring permanent accurate calibration [10], one may speculate that in the prolonged absence of visual feedback (without prior vision) the underlying, primarily incompletely matured neural structures undergo progressive degradation over the course of many years or decades, the final abolition of VOR functioning being due to the irretrievable loss of vestibular connections. The loss of vestibular control is therefore specifically limited to the VOR. Other postural reflexes derived from the vestibular input (vestibulo-spinal reflexes) are not involved, since they must be used particularly for maintaining balance in the light-deprived condition.

A long-lasting deprivation with prior vision can only weaken, and not completely abolish, the VOR (group B); a recent visual loss does not substantially affect the VOR (group C).

It does not seem correct to explain the oculomotor deficits with reference to extraocular muscle dysfunction, however, even though a remarkable optomotor atrophy was clearly recognizable by orbital CT (Fig.7) at least in cases of longstanding (7-65 years) blindness.

\section{References}

1. Bartels M (1914) Über willkürliche und unwillkürliche Augenbewegungen (Nystagmus der Blinden, Proprioreflexe, Blickbewegungen der Tiere). Klin Monatsbl Augenheilk 53:358

2. Bartels M (1928) Beobachtungen an Wirbeltieren und Menschen über unwillkürliche Augenbewegungen bei Störungen des Sehens: Mitteilung 2: Beobachtungen an Menschen. Klin Monatsbl Augenheilk 80:145-176

3. Bender MB (1969) Disorders of eye movements. In: Vinken PJ, Bruyn GW (eds) Handbook of clinical neurology, vol 1. North Holland, Amsterdam, pp 547-630

4. Berthoz A, Jeannerod M, Vital-Durand F, Oliveras JL (1975) Development of vestibulo-ocular responses in visually deprived kittens. Exp Brain Res 23: 425-442

5. Collewijn H (1977) Optokinetic and vestibulo-ocular reflexes in dark-reared rabbits. Exp Brain Res 27:287-300

6. Favilla M, Ghelarducci B, La Noce A (1984) Development of vertical VOR characteristics in intact and flocculectomized rabbits visually deprived from birth. Behav Brain Res 13:209-216

7. Forssman B (1964) Vestibular reactivity in cases of congenital nystagmus and blindness. Acta Otolaryngol (Stockh) 57:539-555

8. Gauthier GM, Hofferer JM (1976) Eye tracking of self-moved targets in the absence of vision. Exp Brain Res 26:121-139

9. Goddé-Jolly D, Larmande A (1973) Les nystagmus. Masson, Paris, p 246

10. Gonshor A, Melvill Jones G (1976) Extreme vestibulo-ocular adaptation induced by prolonged optical reversal of vision. $J$ Physiol (Lond) 256:381-414

11. Harris LR, Cynader M (1981a) The eye movements of the darkreared cats. Exp Brain Res 44:41-56

12. Harris LR, Cynader M (1981b) Modification of the balance and gain of the vestibulo-ocular reflex in the cat. Exp Brain Res 44:57-70

13. Kömpf D, Engelhardt A, Dietrich H-J, Neundörfer B (1985) Die acute cerebelläre Encephalitis im Erwachsenenalter. Nervenarzt 56:431-439.

14. Leigh RJ, Zee DS (1980) Eye movements of the blind. Invest Ophthalmol 19:328-331

15. Ohm J (1950) Der Nystagmus bei Blinden. Graefes Arch Ophthalmol $151: 293-326$

16. Piper H-F, Kömpf D, Neundörfer B (1981) Richtungswechselnder Spontannystagmus mit synchronem Wechsel der Pupillen- und Lidspaltenweite. Okulo-pupillomotorisches Syndrom bei Erblindung im Rahmen einer Dysgenesis mesodermalis iridis et corneae Rieger. Ophthalmologica 182:175-189

17. Redslob E (1927) Le nystagmus des aveugles. Rev Otoneuroophthalmol 5:490-526

18. Steinbach MJ (1969) Eye tracking of self-moved targets: The role of efference. J Exp Psychol 82:366-376

19. Toglia JU (1967) Caloric tests in blind patients. Arch Otolaryngol $86: 298-302$

20. Wiesel TN, Hubel DH (1974) Ordered arrangement of orientation columns in monkeys lacking visual experience. J Comp Neurol 158:307-318

Received June 9, 1986/ Received in revised form December 8, 1986/ Accepted January 22, 1987 